\title{
Oxidative Stress and Antioxidant Status in Patients with Erectile Dysfunction
}

\author{
Alessandra Barassi, MD, ${ }^{*}$ Giovanni M. Colpi, MD, ${ }^{\dagger}$ Guido Piediferro, MD, ${ }^{\dagger}$ Giada Dogliotti, MD, ${ }^{\ddagger}$ \\ Gian Vico Melzi D’Eril, MD, PhD, ${ }^{\star}$ and Massimiliano M. Corsi, MD, PhD ${ }^{\ddagger \S}$ \\ *Dipartimento di Medicina, Chirurgia e Odontoiatria, Polo Universitario San Paolo, Università degli Studi di Milano, \\ Milano, Italia; †U.O. Andrologia, Azienda Ospedaliera San Paolo, Milano, Italia; ¥Istituto di Patologia Generale, Facoltà di \\ Medicina e Chirurgia, Università degli Studi di Milano, Milano, Italia; §Laboratorio di Applicazioni Biotecnologiche, \\ IRCCS Istituto Galeazzi, Milano, Italia \\ DOI: $10.1111 / \mathrm{j} .1743-6109.2009 .01279 . x$
}

\section{A B S T R A C T}

Introduction. Erectile dysfunction (ED) is increasingly recognized as a public health problem. The interaction between nitric oxide and reactive oxygen species is one of the important mechanisms implicated in the pathophysiological process of ED. Plasma contains various antioxidant components to prevent free-radical injury.

Aim. The aim of this study was to determine and compare the oxidative and antioxidant status of peripheral venous blood in patients with ED of arteriogenic and non-arteriogenic origin.

Methods. Oxidative stress and antioxidant status were assessed in 40 patients with ED and 20 healthy controls.

Main Outcome Measures. Plasma reactive oxygen metabolite (ROM) concentrations were measured as an indicator of oxidative stress, and plasma total antioxidant status (TAS) to indicate antioxidant defense.

Results. Plasma ROM concentrations were higher (349.75 \pm 53.35 standard deviation [SD] U.Carr vs. $285.43 \pm 25.58$ U.Carr, $P<0.001)$ and plasma TAS lower $(0.54 \pm 0.16 \mathrm{SD} \mathrm{mmol} / \mathrm{L}$ vs. $0.94 \pm 0.28 \mathrm{SD} \mathrm{mmol} / \mathrm{L}$, $P<0.0001)$ in patients with arteriogenic ED in comparison to those in patients with non-arteriogenic ED. Plasma ROM and TAS in controls were not significantly different from those in non-arteriogenic ED.

Conclusions. This observation may be useful to better understand and distinguish arteriogenic from nonarteriogenic ED using laboratory tests. In addition, our findings provide important support for an antioxidant therapy to try to correct oxidative stress in arteriogenic ED patients. Barassi A, Colpi GM, Piediferro G, Dogliotti G, Melzi D'Eril GV, and Corsi MM. Oxidative stress and antioxidant status in patients with erectile dysfunction. J Sex Med 2009;6:2820-2825.

Key Words. Erectile Dysfunction; Oxidative Stress; Reactive Oxygen Metabolite; Total Antioxidant Status

\section{Introduction}

$\mathrm{E}$ rectile dysfunction [1] (ED) is defined as the inability to achieve or maintain erections sufficient for satisfactory sexual intercourse. While up to the 1980s, ED was considered to be primarily a psychogenic disease, extensive research efforts have proven that ED is caused by organic disease in up to $80 \%$ of cases [2]. Penile erection results from the interaction of different physiologic systems involving the central and peripheral nervous system, and endothelial and vascular smooth muscle cells of the corpora cavernosa [3]. There is growing interest among researchers in the role of oxidative stress in the pathophysiolo- gical mechanism of ED [4]. The mechanism of oxidative injury is thought to involve lipid peroxidation, protein oxidation, DNA oxidation, decreased synthesis, and bioavailability of nitric oxide (NO), which is probably the principal neurotransmitter mediating penile erection $[5,6]$. Free-radical injury is prevented by exogenous antioxidants, such as vitamins $\mathrm{E}$ and $\mathrm{C}$, and also by endogenous antioxidants, such as scavenger enzymes (superoxide dismutase, catalase, and glutathione peroxidase), bilirubin, and uric acid. Under some conditions, increases in oxidants and decreases in antioxidants cannot be prevented, and the oxidative/antioxidative balance shifts toward the oxidative status. Basic scientific studies indicate 
that oxidative stress may have a role in impaired cavernosal function, such as in ED [7,8]. The aims of this study were to compare the metabolic status of patients with arteriogenic and non-arteriogenic $\mathrm{ED}$, and to assess the metabolic differences between the two and the healthy subjects.

\section{Material and Methods}

\section{Investigation Protocol}

In our center, patients complaining of ED are currently investigated by careful history-taking and clinical andrological examination, then, a few days later, by a panel of examinations, including blood tests, complete blood picture, hemoglobin, glycated hemoglobin, glycemia, urea, creatinine, C-reactive protein (CRP), total cholesterol and HDL, triglycerides, transaminases, testosterone, prolactin, estradiol, urine analysis and 24 hours microalbuminuria, the International Index of Erectile Function questionnaire (IIEF), and echocolor-Doppler of both cavernous arteries.

The IIEF questionnaire [9] is a validated, selfadministered tool $[9,10]$, but we only evaluated the answers to the first 5 (erectile response dominium) of the 15 questions (IIEF-15, 1-5).

Penile echo-color-Doppler was done in basal conditions and after intracavernous injection of $10 \mathrm{mcg}$ prostaglandin $\mathrm{E} 1$ (PgE1), and the peak systolic velocity (PSV) and end-diastolic velocity (EDV) were recorded 5, 10, 15, 20, and 25 minutes after the injection in the proximal portion of the penis. Patients were classified as "nonarteriogenic" when their PSV was $\geq 35 \mathrm{~cm} /$ second, or $\leq 35 \mathrm{~cm} / \mathrm{second}$ but $>25 \mathrm{~cm} / \mathrm{second}$ with concomitant EDV $\leq 0 \mathrm{~cm} / \mathrm{second}$, and "arteriogenic" when their PSV was $\leq 20 \mathrm{~cm} / \mathrm{second}$. The erection quality was estimated 20 minutes after each injection. If a patient appeared stressed, he was given a second injection of the same dose of $\mathrm{PgE} 1$ and all measurements were repeated.

From 30 to 60 minutes after the penile echocolor-Doppler, participants were placed in a supine position and blood samples were drawn from a cubital vein into EDTA tubes. Samples were immediately stored on ice and centrifuged at $4^{\circ} \mathrm{C}$, 3,000 rpm, for 10 minutes. The plasma samples were separated and stored at $-80^{\circ} \mathrm{C}$ until analysis.

\section{Reactive Oxygen Metabolites (ROMs) and Total Antioxidant Status (TAS) Testing}

ROMs were measured in plasma by a spectrophotometric assay (d-ROMs test, Diacron, Italy), kindly provided by the manufacturers and used following their instructions. The test measures the plasma levels of ROMs such as hydroperoxides generated in cells as a consequence of the respiratory burst. The test exploits the hydroperoxides' ability to generate free radicals in the presence of transition metals ( $\mathrm{Fe}, \mathrm{Cu}$, etc.) that act as catalysts. When free radicals react with a correctly buffered chromogenic substance, they develop a colored complex that can be measured photometrically at $505 \mathrm{~nm}$ (UVICAM, Cambridge, UK). The concentration of the colored complex is directly proportional to the concentration of hydroperoxides. Results are expressed in arbitrary units, called Caratelli Units (U.Carr). One U.Carr corresponds to $0.08 \mathrm{mg}$ of $\mathrm{H}_{2} \mathrm{O}_{2}$ per $100 \mathrm{~mL}$.

High levels of ROM indicate oxidative stress. Low concentrations have been reported during antioxidant supplementation or in patients under treatment with corticosteroids [11].

According to the end-point analysis, the absorbances must be measured after incubating a solution of $5 \mu \mathrm{L}$ of plasma, $1 \mathrm{~mL}$ of chromogenic mixture, and $10 \mu \mathrm{L}$ of acetate buffer at $37^{\circ} \mathrm{C}$ for 75 minutes. The intra-assay coefficient of variation (CV) on 20 samples of a fresh plasma pool was $2.2 \%$, and the inter-assay $\mathrm{CV}$, measuring in 10 different days the same plasma samples stored frozen, was $3.7 \%$. Accuracy was evaluated using a control serum with assigned value, provided by the manufacturer. The method was linear up to 500 U.Carr.

The TAS in the plasma in $\mathrm{mmol} / \mathrm{L}$ was established with the RANDOX NX2332 test (RANDOX Laboratories Ltd., Ardmore, UK). The method is based on incubation of $\operatorname{ABTS}^{\circledR}(2,2$ azinobis 3-ethylbenzthiazoline sulfate) with metmyoglobin and $\mathrm{H}_{2} \mathrm{O}_{2}$, which may lead to the formation of ABTS-derived radicals. These have a stable blue-green color at the wavelength of $600 \mathrm{~nm}$. Antioxidants in the sample weaken the color in proportion to their concentration. The test included phosphate buffer $(5 \mathrm{mmol} / \mathrm{L}$, $\mathrm{pH} 7.4)$, met-myoglobin $(6.1 \mu \mathrm{mol} / \mathrm{L})$, and hydrogen dioxide $(250 \mu \mathrm{mol} / \mathrm{L})$. Absorbance was recorded after incubation of 3 minutes at $37^{\circ} \mathrm{C}$ at $600 \mathrm{~nm}$ using a spectrophotometer (UVICAM, Cambridge, UK). The intra-assay coefficient of variation (CV) on 20 samples of a fresh plasma pool was $3.6 \%$ and the inter-assay $\mathrm{CV}$, measuring in 10 different days the same plasma sample stored frozen, was $6.0 \%$. To avoid the effect of a diurnal variation of ROM and TAS, the eco-color Doppler procedure and drawing the blood samples were 
done between 9:00 and 12:00 $\mathrm{Am}$ to the entire population [12]. The possible consequences of the stress, injection, and needle trauma were not different in the two populations because all the patients were investigated in the same way.

\section{Patients and Control Group}

Out of a series of 228 filed ED cases studied in the period October 2005-June 2007, we randomly selected 20 arteriogenic patients (group A) and 20 non-arteriogenic patients (group B), according to our inclusion criteria for this study, for a total of 40 cases (mean age 44 years, range $24-60$ years). The inclusion criteria were: no clinical evidence from the patient's clinical history of coronary artery disease, hypertension, malignancy, renal failure, congestive heart failure, systemic inflammatory disease, or arrhythmias, and no current smoking [13] and no vitamins supplementation. We excluded even the subjects affected by diabetes mellitus because the redox status of these patients has already been deeply investigated: in these patients, macro- and micro-angiopathy are related, not only to oxidative stress, but also to endothelial impairment [14].

The 20 healthy controls were all blood donors (mean age 42.1 years, range 25-53 years), and, according to their answers to the first five IIEF-15 questions (erectile response domain), did not suffer from ED. Both healthy controls and the patients of the two groups declared to develop a normal physical activity.

In accordance with the Declaration of Helsinki II, the design of the study was explained thoroughly to all participants, and informed consent was obtained for ROM and TAS testing from all the 228 filed ED patients and the 20 controls, and for administering the IIEF-15 test to controls. In particular, it was explained to the participants that no additional blood was needed for this study.

\section{Statistical Analysis}

The results are given as mean \pm standard deviation (SD). Groups were compared by one-way analysis of variance. Linear regression analysis was also done between experimental variables. Significance was established as $P<0.05$. Post hoc comparisons in logical sets of means were done using the Tukey-Kramer multiple comparisons test (Instat, GraphPAd, CA, USA).

\section{Results}

In Group A (20 arteriogenic ED men; mean age 48 years, range $26-59$ years), IIEF values were: mean

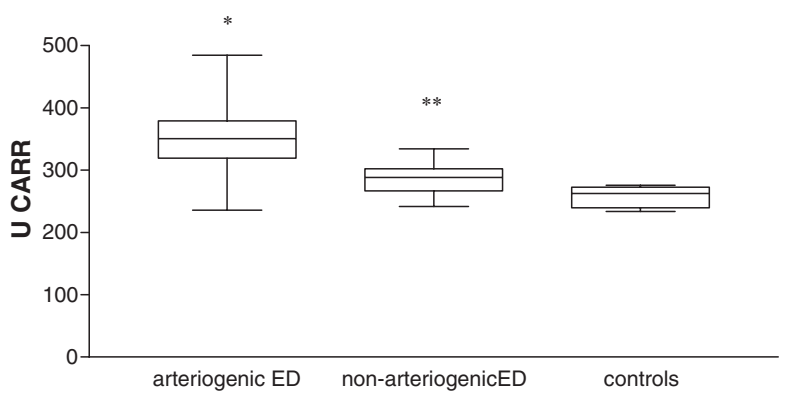

Figure 1 Reactive oxygen metabolites (ROMs) expressed in U.Carr (mean $\pm \mathrm{SD}$ ). The figure shows the differences between Group A (men with arteriogenic erectile dysfunction), Group B (non-arteriogenic erectile dysfunction), and controls. The ROM concentrations were significantly higher in Group A than in Group B $(P<0.001)$, and than in the controls $(P<0.001)$. There were no appreciable differences between Group B and the controls $(P>0.05)$.

10.30, median 11.00 (range 0-20). In Group B (20 non-arteriogenic ED men; mean age 41 years, range 24-60 years), the respective figures were 12.75 and 14.00 (range $0-20$ ). There were no significant differences between the two groups $(P>0.05)$.

ROM, a parameter of oxidative stress, was determined in the plasma of ED patients. Plasma ROM concentrations were significantly higher in Group A than in Group B $(349.75 \pm 53.35$ SD U.Carr vs. $285.43 \pm 25.58$ SD U.Carr, $P<0.001$ ), and than in the controls $(257.7 \pm 15.96 \mathrm{SD}$ U.Carr, $P<0.001)$. There were no appreciable differences between Group B and the controls $(P>0.05)$ (Figure 1).

The plasma TAS concentration, a measure of the antioxidant status, was lower in Group A than in Group B $(0.54 \pm 0.16 \mathrm{SD} \mathrm{mmol} / \mathrm{L}$ vs. $0.94 \pm 0.28 \mathrm{SD} \mathrm{mmol} / \mathrm{L}, P<0.0001)$ and also than in the controls $(1.06 \pm 0.24 \mathrm{SD} \mathrm{mmol} / \mathrm{L}$, $P<0.0001)$. There were no significant differences between Group B and the controls $(P>0.05)$ (Figure 2).

The plasma CRP level was not significantly different $(P>0.05)$ between Group A $(3.3 \pm 0.7 \mathrm{mg} / \mathrm{L})$ and Group B $(2.9 \pm 0.9 \mathrm{mg} / \mathrm{L})$.

\section{Discussion}

This study shows a typical pattern of oxidative stress in patients with arteriogenic ED. We found a significant increase of ROM plasma levels and a simultaneous significant decrease of plasma TAS concentration in arteriogenic ED subjects compared to non-arteriogenic ED subjects and healthy 


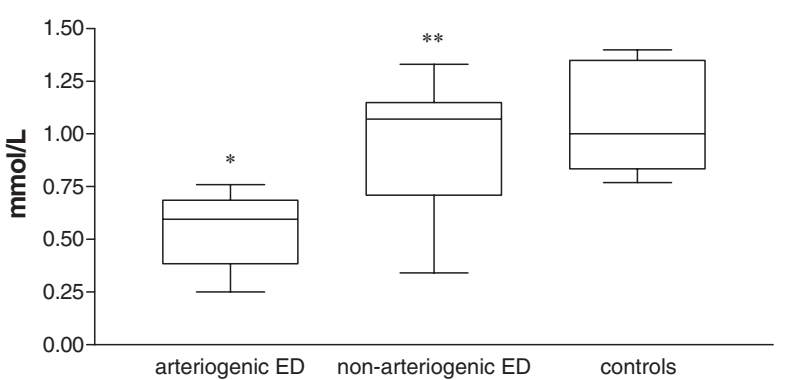

Figure 2 Total antioxidant status (TAS) expressed in $\mathrm{mmol} / \mathrm{L}$ (mean $\pm \mathrm{SD}$ ). The figure shows the differences between Group A (men with arteriogenic erectile dysfunction), Group B (non-arteriogenic erectile dysfunction), and controls. The TAS concentration was lower in Group A than in Group B $(P<0.0001)$, and also than in the controls $(P<0.0001)$. There were no significant differences between Group B and the controls $(P>0.05)$.

non-ED controls. The populations studied, ED and non-ED, were homogeneous and without any atherosclerotic risk factors. Considering that ROM reflects the amount of oxidative stress and TAS a measure of the antioxidant status, our data indicate the presence of an imbalance between pro-oxidant and the protective mechanisms conferred by antioxidants only in arteriogenic ED patients.

Erectile dysfunction is a widespread health problem with an estimated worldwide prevalence of more than 150 million cases in 1995, which will increase to approximately 322 million by 2025 [15]. The functional state of the penis is regulated by the balance of vasoactive substances, which either contract or relax the vessels and smooth muscle cells in the corpora cavernosa [16]. Functional and expression studies suggest that NO, derived from vascular endothelial and neural sources, plays an essential role in the early steps of the normal cascade of relaxation of the penile vasculature and cavernous smooth muscle $[5,3,17]$. The interaction between NO and ROM is one of the important mechanisms implicated in the pathophysiological process of ED [18]. The presence of oxygen-free radicals inactivates $\mathrm{NO}$ and, therefore, reduces the effective NO concentration available for cavernosal muscle relaxation. The data presented in this report support the hypothesis that the increased oxidative stress, together with decreased antioxidant status, contributes at least in part to ED of arteriogenic origin. The number of patients included in this study may seem low, but it must be considered that the population studied is very selected. In this way, we could compare the metabolic status of patients with arte- riogenic and not arteriogenic ED without any confounding factors. The population studied had no clinical evidence of atherosclerotic diseases and was free of the common risk factors associated with generalized penile arterial insufficiency like hypertension, hyperlipidemia, cigarette smoking, diabetes mellitus, and pelvic irradiation [19,20]. However, only arteriogenic ED subjects had increased ROM and decreased TAS concentrations if their sources in the penis remain largely unknown [21]. A fairly recent study showed that plasma TAS of peripheral blood may reflect the TAS of penile cavernosal blood [22]. In conclusion, oxidative stress seems to be a common component of arteriogenic ED in line with data recently reported by Musicki and Burnett [23].

On the possible clinical relevance of these findings, we propose that the TAS and ROM assays might serve as indicators of metabolic status in all ED patients. When antioxidant levels are measured in plasma, it is not possible to determine the origin of these molecules. The question remains whether antioxidant abnormalities represent the proverbial egg or chicken dilemma. It appears likely that these changes are not the cause, but might be the consequence of the ROM excess. Thus, the oral supplementation of antioxidants may be an effective approach, and the arteriogenic ED subjects may benefit from an antioxidant treatment [24]; otherwise, the treatment of sildenafil citrate could be useful for its protective effects on oxidative stress by inhibiting free-radical formation and by supporting an antioxidant redox system, as recently reported [25].

\section{Conclusions}

Caution must be exercised in ascribing causality when increased free-radical activity is found to be associated with disease processes, as oxidative damage may be a consequence rather than a cause of tissue injury [26]. However, these purely preliminary findings do appear to confirm that increased generation of free radicals and deficiencies of antioxidant defense can be an important etiological factor in vascular ED. Quite likely, the high plasma ROM levels precede the reduction in PSV in the cavernous arteries, shown by echocolor-Doppler examination. Longitudinal studies are currently in progress to see whether changes in endothelial dysfunction after antioxidant treatment can delay the appearance of major vascular complications in impotent patients. 


\section{Acknowledgment}

We thank Ms. Judy Baggott for editing the manuscript.

Corresponding Author: Alessandra Barassi, MD, Dipartimento di Medicina, Chirurgia e Odontoiatria, Università degli Studi di Milano, Via di Rudinì 8, Milano 20142, Italy. Tel: 393355444121; Fax: 3981844027; E-mail: alessandra.barassi@unimi.it

Conflict of Interest: None declared.

\section{Statement of Authorship}

Category 1

(a) Conception and Design

Alessandra Barassi; Massimiliano M. Corsi

(b) Acquisition of Data

Giada Dogliotti; Guido Piediferro; Giovanni M. Colpi

(c) Analysis and Interpretation of Data

Gian Vico Melzi D'Eril; Alessandra Barassi, Massimiliano M. Corsi

\section{Category 2}

(a) Drafting the Article

Giada Dogliotti; Guido Piediferro; Giovanni M. Colpi

(b) Revising It for Intellectual Content Gian Vico Melzi D’Eril; Massimiliano M. Corsi

\section{Category 3}

(a) Final Approval of the Completed Article Alessandra Barassi; Gian Vico Melzi D'Eril; Massimiliano M. Corsi; Giovanni M. Colpi

\section{References}

$1 \mathrm{NIH}$ Consensus Conference. Impotence. NIH Consensus Development Panel on impotence. JAMA 1993;270:83-90.

2 Sullivan ME, Keoghane SR, Miller MAW. Vascular risk factors and erectile dysfunction. BJU Int 2001;87:838-45.

3 Anderson KE, Wagner G. Physiology of penile erection. Physiol Rev 1995;75:191-236.

4 De Young L, Yu D, Bateman RM, Brock GB. Oxidative stress and antioxidant therapy: Their impact in diabetes-associated erectile dysfunction. J Androl 2004;25:830-6.

5 Burnett AL, Lowenstein CJ, Bredt DS, Chang TS, Snyder SH. Nitric oxide: A physiologic mediator of penile erection. Science 1992;257:401-3.

6 Ignarro LJ, Bush PA, Buga GM, Wood KS, Fukuto JM, Rajfer J. Nitric oxide and cyclic GMP formation upon electrical field stimulation cause relaxation of corpus cavernosum smooth muscle. Bichem Biophys Res Commun 1990;170:843-50.
7 Jones RW, Rees RW, Minhas S, Ralph D, Persad RA, Jeremy JY. Oxygen free radicals and the penis. Expert Opin Pharmacother 2002;3:889-97.

8 Hamed EA, Meki AR, Gaafar AA, Hamed SA. Role of some vasoactive mediators in patients with erectile dysfunction their relationship with angiotensinconverting enzyme and growth hormone. Int J Impot Res 2003;15:418-25.

9 Rosen RC, Cappelleri JC, Smith MD, Lipsky J, Pena BM. Development and evaluation of an abridged, 5-item version of the International Index of Erectile Function (IIEF-5) as a diagnostic tool for erectile dysfunction. Int J Impot Res 1999;11:31926.

10 Rosen RC, Riley A, Wagner G, Osterloh IH, Kirkpatrick J, Mishra A. The International Index of Erectile Function (IIEF): A multidimensional scale for assessment of erectile dysfunction. Urology 1997;49:822-30.

11 Banfi G, Malavazos A, Iorio E, Dolci A, Doneda L, Verna R, Corsi MM. Plasma oxidative stress biomarkers, nitric oxide and heat shock protein 70 in trained elite soccer players. Eur J Appl Physiol 2006;96:483-6.

12 Hirayama J, Cho S, Sassone-Corsi P. Circadian control by the reduction/oxidation pathway: Catalase represses light-dependent clock gene expression in the zebrafish. Proc Natl Acad Sci USA 2007;104:15747-52.

13 Tostes RC, Carneiro FS, Lee AJ, Giachini FR, Leite R, Osawa Y, Webb RC. Cigarette smoking and erectile dysfunction: Focus on NO bioavailability and ROS generation. J Sex Med 2008;5:1284-95.

$14 \mathrm{Ha} \mathrm{H}$, Hwang IA, Park JH, Lee HB. Role of reactive oxygen species in the pathogenesis of diabetic nephropathy. Diabetes Res Clin Pract 2008;82(Suppl 1):S42-5.

15 Ayta IA, McKinlay JB, Krane RJ. The likely worldwide increase in erectile dysfunction between 1995 and 2025 and some possible policy consequences. BJU Int 1999;84:50.

16 Anderson KE. Pharmacology of penile erection. Pharmacol Rev 2001;53:417-50.

17 Moreland RB, Hsieh G, Nakane M, Brioni JD. The biochemical and neurologic basis for the treatment of male erectile dysfunction. J Pharmacol Exp Ther 2001;296:225-34.

18 Jones RW, Rees RW, Minhas S, Ralph D, Persad RA, Jeremy JY. Oxygen free radicals and the penis. Expert Opin Pharmacother 2002;3:889-97.

19 Levine FJ, Greenfield AJ, Goldstein I. Arteriographically determine occlusive disease within the hypogastric-cavernous bed in impotent patients following blunt perineal and pelvic trauma. J Urol 1990;144:1147-53.

20 Rosen MP, Greenfield AJ, Walker TG, Grant P, Dubrow J, Bettmann MA, Fried LE, Goldstein I. Cigarette smoking: An independent risk factor for atherosclerosis in the hypogastric-cavernous bed of 
men with arteriogenic impotence. J Urol 1991; 145:759-63.

21 Jeremy JY, Jones RA, Koupparis AJ, Hotston M, Persad R, Angelini GD, Shukla N. Reactive oxygen species and erectile dysfunction: Possible role of NADPH oxidase. Int J Impot Res 2007;19:265-80.

22 Yeni E, Gulum M, Selek S, Erel O, Unal D, Verit A, Savas M. Comparison of oxidative/antioxidative status of penile corpus cavernosum blood and peripheral venous blood. Int J Impot Res 2005; 17:19-22.

23 Musicki B, Burnett AL. eNOS function and dysfunction in the penis. Exp Biol Med (Maywood) 2006;231:154-65.

24 Angulo J, Peiró C, Cuevas P, Gabancho S, Fernández A, González-Corrochano R, La Fuente JM,
Baron AD, Chen KS, de Tejada IS. The Novel Antioxidant, AC3056 (2,6-di-t-butyl-4((Dimethyl-4Methoxyphenylsilyl)Methyloxy)Phenol), reverses erectile dysfunction in diabetic rats and improves NO-mediated responses in penile tissue from diabetic men. J Sex Med 2009;6:373-87.

25 Perk H, Armagan A, Naziroglu M, Soyupek S, Hoscan MB, Sütcü R, Ozorak A, Delibas N. Sildenafil citrate as a phosphodiesterase inhibitor has an antioxidant effect in the blood of men. J Clin Pharm Ther 2008;33:635-40.

26 Halliwell B. Free radicals, antioxidants and human disease: Curiosity, cause or consequence? Lancet 1994;344:721-4. 